\title{
Da mediação fenomenológica, para a emergência de uma nova corporeidade. 0 corpo coletivo como uma forma performativa do século XXI
}

\author{
De la médiation phénoménologique, vers l'émergence de corporéités inédites. \\ Le corps collectif comme forme performative du XXième siècle
}

\author{
Isabelle Choinière ${ }^{1}$ \\ Université du Québec à Montréal/UQAM \\ Tradução: Cristina Miranda de Almeida
}

\begin{abstract}
Resumo
Este artigo pretende analisar uma abordagem de pesquisa-criação, que tem como objetivo desenvolver uma visão diferente do corpo performativo através do seu contacto com a tecnologia, e com especial atenção para a reintrodução do corpo, e sua inteligência específica, na compreensão e construção da relação entre somática e tecnologia. Este capítulo defende a hipótese de que a tecnologia, utilizada nestas experiências como uma físicalidade (Leroi-Gourhan, [1945], 1973), torna-se um elemento ativador de um processo de reconfiguração sensório-perceptiva (Pitozzi, 2010b), que tem o potencial de desenvolver, não uma corporeidade única, mas várias corporalidades novas decorrentes da modificação, física e fenomenológica, do efeito da tecnologia sobre o corpo performativo em movimento. Para fazer o exame destas alterações e emergências, a análise será feita desde o ângulo do corpóreo, que é uma interpretação ontológica mais recente do corpo performativo (Bernard, 2001; Perrin, 2006), que sugere a compreensão do corpo como uma abertura, uma encruzilhada de influências e relações, uma realidade instável feito de redes de intensidades (Merleau-Ponty, 1945; Deleuze e Guattari, 1980; Rolnik, 2006). Sugiro analisar essas manifestações de corporeidade, o que é possível obter através de uma mudança ontológica do corpo quando está sob a ação da, e ativado pela, tecnologia. É, portanto, uma abordagem que tem em conta uma ontologia instável. Seguindo este processo analítico vamos, então, ser capazes de sugerir que esta mudança ontológica do corpo - tornada possível pela consideração da sua mediação - traz a evolução das formas de corporeidade.
\end{abstract}

Palavras-chave

Somático; tecnologia; mediação; fenomenologia; cambio ontológico; corporeidade.

\section{Résumé}

Cet article vise à examiner une approche de recherche-création qui avait pour but de développer une vision différente du corps performatif à travers son contact avec la technologie, et ceci en portant une attention particulière sur la réintroduction du corps et son intelligence spécifique dans la compréhension et la construction du rapport somatique et

${ }^{1} \mathrm{PhD}$ pelo Planetary Collegium, Transdisciplinary Research, Plymouth University (RU), Choinière é pesquisadora e artista internacional, bem como professora de novas cenas performativas contemporâneas que incorporam a tecnologia. Sua pesquisa é publicada e traduzida em francês, inglês e português. Em 2019, seu livro: Le prisme des sens: médiation et nouvelles 'réalités' du corps será publicados três 3 línguas. Ela é professora associada (Escola de mídia), pesquisadora pós-doutoral (Faculdade de Artes) da Universidade de Quebec em Montreal, bem como Professora Visitante da Universidade do Chile 
technologie. Cet article défend l'hypothèse que la technologie, utilisée dans ces expérimentations comme une physicalité (Leroi-Gourhan, [1945] 1973), devient l'activateur d'un processus de reconfiguration sensori-perceptuel (Pitozzi, 2010b) qui aura le potentiel de développer, non pas une seule corporéité, mais de multiples nouvelles corporéités issues de la modification physique et phénoménologique de l'effet de la technologie sur le corps performatif en mouvement. Pour faire l'examen de ces altérations et émergences, l'analyse se fera sous l'angle de la corporéité, soit une interprétation ontologique plus récente du corps performatif (Bernard, 2001; Perrin, 2006), qui propose de comprendre le corps comme une ouverture, un carrefour d'influences et de relations, une réalité mouvante faite de réseaux d'intensités (Merleau-Ponty, 1945; Deleuze \& Guattari, 1980; Rolnik, 2006). Je propose d'analyser ces manifestations de la corporéité qui deviennent possibles par un déplacement ontologique du corps lorsqu'il est sous l'action, et activé, par la technologie. C'est donc une approche qui prend en compte une ontologie en mouvance. En suivant ce processus analytique, nous serons en mesure de suggérer que ce déplacement ontologique du corps rendant possible la prise en compte de sa médiation-, amène l'évolution des formes de la corporéité.

Mots clés

Somatique; technologie; médiation; phénoménologie; déplacement ontologique; corporéité.

\subsection{Introdução}

Nas últimas décadas o cenário contemporâneo sentiu os efeitos de uma ruptura epistemológica fundamental - uma mudança de perspectiva nas artes e sobre as artes, particularmente nas artes ao vivo - que redefine a noção de performatividade à luz da tecnologia. Para os artistas, uma possível razão do interesse de fazer um trabalho de pesquisa-criação que envolve tecnologia, é que ele pode revelar aspectos desconhecidos do corpo, ao mesmo tempo que reflete uma visão sobre nós mesmos/as, mostrando os circuitos internos escondidos e a reorganização dos elementos que constituem, e continuamente transformam, nossos corpos, o meio ambiente, e, no contexto das artes e performances, artistas e espectadores que agem e definem -se como sujeitos.

Esta é a busca que serviu de base e motor da pesquisa que realizei entre 2015 e 2016, cujo objetivo era articular uma visão diferente do corpo performativo em seu contato com a tecnologia. A minha abordagem nesta pesquisa foi desenvolvida sob 0 ângulo da corporeidade, que se baseia em interpretações ontológicas recentes do corpo performativo (BERNARD, 2001; PERRIN, 2006), como uma abertura, ou encruzilhada, de influências e relações, uma realidade instável, composto de redes de intensidades (MERLEAU-PONTY, 1945; DELEUZE E GUATTARI, 1980; ROLNIK, 2006). Este capítulo descreve, assim, um processo artístico que envolve o que eu vejo como uma mudança ontológica do corpo ocorrendo com o contato com a tecnologia e através deste mesmo contato. Este capítulo perfila claramente dois modelos performativos emergentes que venho desenvolvendo: em primeiro lugar, o que eu chamo de "corpo físico coletivo" e em segundo lugar, um "corpo de som", ou "corpo mediado coletivamente". Estes modelos refletem uma abordagem artística 
que destaca um modelo que ativa "formas de potencialidade corporal' (CHOINIERE, 2013, 2014).

De acordo com Michel Blay, filósofo e diretor de investigação no Centre Nacional de la Recherche Scientifique (CNRS), em Paris, o termo ontologia pode ser entendido no sentido de "questionar alguma coisa", a fim de ver se esta coisa existe ou não (BLAY, 2006). Para Dermot Moran, um filósofo irlandês especializado em fenomenologia e filosofia medieval, "a ontologia é entendida em termos fenomenológicos como não apenas o que os seres são, mas como formas ou modos de ser; a ontologia considera como chegamos a ser em um sentido dinâmico" (MORAN, 2000: 358). Estas duas interpretações da ontologia se alinham com a perspectiva que adotei para pesquisar possíveis mudanças ontológicas do corpo em seu contato com a tecnologia, - e para investigar e propor um entendimento diferente do corpo performativo. Esta pesquisa, aqui apresentada, tomou a forma de uma proposição estética que revela um tipo emergente de corporeidade resultante de uma dissolução das fronteiras psicofísicas (ROLNIK, 2006, n.d.b). Esta dissolução da fronteira psico-corporal, que pode levar a viver uma intercorporeidade (tipo de intersubjetividade corporal no contexto das artes performativas), implica o desaparecimento da oposição entre sujeito e objeto. Isto é possível se a tecnologia é considerada um ativador da renovação sensorial pela desestabilização da percepção e da organização sensorial (mapeamento) que determina o experiencial.

Várias etapas marcaram esta investigação, especialmente um interesse em "pesquisacriação" desenvolvido dentro do contexto dos novos cenários performativos interdisciplinares contemporâneos que incorporam tecnologias. A primeira fase da pesquisa foi realizada em 2005 (Quebec), seguida pela segunda fase em 2006 (França e Quebec), uma terceira etapa que conduziu à criação do trabalho intitulado Meat Paradoxe (20072008), seguido de outro trabalho, Flesh Waves (fase \# 4, 2013), e da fase final de pesquisa (\# 5) ainda em andamento. $O$ objetivo desta pesquisa foi investigar e desenvolver um "corpo físico coletivo": um novo modelo performativo (BOISCLAIR, 2007; PITOZZI 2014, 2016; DAVIDSON, 2015) composto por cinco bailarinos em constante contato, cujos movimentos e relações criam um "corpo sonoro coletivo" e geram uma partitura sonora em tempo real, espacializada no ambiente global e tridimensional da atuação. Cada fase do projeto explorou os modos como estes dois "corpos" ou entidades -o "corpo físico coletivo" e "corpo sonoro coletivo"- poderiam ser vistos como interdependentes e inter-relacionados. O corpo coletivo é também um exemplo do tipo de modelo performativo baseado nesta 'época de complexidade' e interação -e conduzente a um "método" considerado complexoprevisto por Edgar Morin $(1977,1981)$ entre outros, Suely Rolnik (nd/b), Réda Benkirane (2002) e Enrico Pitozzi (CHOINIĖRE, DAVIDSON \& PITOZZI, em curso).

\section{I.0.1. Somática e tecnologia}

Embora o âmbito desta nova forma de pesquisa-criação é grande -novas cenas performativas contemporâneas que integrem tecnologias-, o foco será colocado aqui em abordagens que adoptam a exploração somática como elemento principal e que, no contexto do meu trabalho, foram empregadas como uma técnica do corpo e integradas no meu processo criativo e na minha atuação. As práticas somáticas se centram na consciência corporal e envolvem uma série de habilidades de aprendizagem relacionadas 
com a interação sinérgica entre consciência, movimento e meio ambiente. Estas práticas podem, portanto, ser descritas como constituintes de um estudo experimental da corporeidade. Este capítulo delineará perspectivas recentes que incorporam novas manifestações, dinâmicas e polinizações cruzadas entre o somático e a tecnologia (DAVIDSON, 2013; BATSON, 2009; FRALEIGH, 1987; HACKNEY, 1998). E, ainda, refletir sobre a experiência e concepção do corpo performativo na ligação que entretém com a tecnologia à luz de uma abordagem fenomenológica, na que a somática também está implícita (KOZEL, 2007; PITOZZI, 2010A; SHARIR, 2012).

As abordagens criativas decorrentes deste "re-encontro experimental" -entre a parte corporal/somática e a tecnología libertam-se do que Rieusset-Lemarié chamou de "fantasma da contaminação agitado pelos medos de cada forma de arte de perder a sua identidade" (RIEUSSET-LEMARIÉ, 2005: 87). A pesquisa em dança e tecnologia tem raízes na natureza frequentemente interdisciplinar da dança pós-moderna e das artes visuais norte-americanas (entre 1960 e final dos anos 1970). Hoje, no entanto, os/as coreógrafos/as estão dando maior atenção às relações entre os aspectos somáticos e tecnologia (1995 - presente). Esta tendência pode ser vista nas obras de Carol Brown (N.Z.), Jean-Marc Matos (FR.), Susan Kozel (Suécia) ou Kitsous Dubois (FR.), uma artista que trabalha com o corpo em relação com a gravidade zero e a micro-gravidade.

De acordo com uma análise do artista, teórico, professor especializado em dança e novas mídias e co-organizador da conferência internacional Somática e Tecnologia, Andrea Davidson, minha própria experimentação artística constitui "uma área de pesquisa que examina as interligações entre percepção, experiência sensual, conhecimento corporal e práticas, processos e conceitos contemporâneos que integram novos meios [...]. Tal pesquisa raramente tem sido formalmente identificada com o campo especializado da somática" (DAVIDSON, 2013: 3). Reflete, portanto, uma abordagem artística recente que emana especificamente de uma prática coreográfica integrada com a tecnologia que está firmemente ancorada na somática.

Esta experimentação é específica ao abordar o corpo tanto como base para a criação coreográfica, como para testar os efeitos da tecnologia sobre o mesmo corpo. Esta abordagem assume que, em primeiro lugar, a tecnologia deve ser 'vivida'2 a fim de ser entendida (LEROI- GOURHAN, [ 1943 ] 1971, [ 1945 ] 1973). Isso reflete uma abordagem fundamentalmente fenomenológica em relação com a tecnologia, que implica o corpo tanto a dimensão física como a evolução para outras formas de corporeidade, isto é, uma abordagem através do corpo como ele é experimentado em um ambiente tecnológico em que artistas e espectadores, estão imersos.

\footnotetext{
20 autor apresenta o fenômeno da evolução humana e tecnológica como uma combinação absoluta que relaciona as mudanças do corpo as necessidades de adaptação ao ambiente, e as alterações do ambiente para satisfazer necessidades do corpo. Assim, "[...] 0 grupo humano assimila seu ambiente através de um conjunto de objetos (instrumentos, meios) " ( [ 1945 ] , 1973: 332). Ele chamou tecnologia, o estudo desta entorno (envelope) superficial. Leroi-Gourhan combina o desenvolvimento técnico com o gesto, estudando assim a tecnologia com o gesto associado a ela. Leroi-Gourhan construiu o seu argumento desde a perspectiva do corpo e da experiência: "A máquina aparece como um dispositivo que não só frequentemente incorpora uma ferramenta, mas principalmente uma ou mais ações" (ibid.: 112-113).
} 
A noção de ambiente também compreende uma das bases do campo da somática. Isso não só implica a consciência do próprio corpo como um ambiente de percepção, mas também leva em conta a relação e interação ativa do corpo com o meio ambiente em geral. No meu trabalho, isso se expressa tanto em termos de destacar a natureza experimental do corpo e em expor a crescente complexidade e multiplicação de formas de corporeidade emergentes através do contato com a tecnologia (CHOINIERE, 2015). Esta consideração primordial do experiencial - aqui, um ponto de partida para a criação de trabalho artístico e um dos principais eixos de minha pesquisa - pode ser relacionada com a definição grega antiga da estética, como uma referência à sensação e à capacidade de perceber. A minha experimentação procurou, assim, desenvolver a consciência sensorial e perceptiva aumentadas e também, investir em uma dimensão da relação somática-tecnologia que pode potencialmente levar a uma transformação da pessoa consigo mesma, da relação com os outros e com o mundo.

Esta orientação foi condicionada pela ideia de que a tecnologia pode ter um papel importante a desempenhar enriquecendo a natureza experimental do projeto e não, pelo contrário, de provocar uma perda ou submissão do corpo à tecnologia. Eu queria evitar a instrumentalização que muitas vezes caracteriza as relações entre o corpo e tecnologia performativa (CHOINIERE, 2013, 2014). A minha ideia era, sim, que a dimensão somática, intermodal, relacional e interdisciplinar da dança poderia gerar novas formas e características criativas, e que através de tal concepção e uso de tecnologia, a linguagem coreográfica poderia ser uma fonte para a geração de novos comportamentos performativos e modelos estéticos. Aqui, a interdisciplinaridade, entendida como um processo artístico polimórfico que não pode ser contido dentro de um campo artístico único, também cria a possibilidade de uma dinâmica nómada que, num espírito de associações livres, explora e promove uma mistura de formas, processos e significado. 0 termo "dinâmica nómada" é, portanto, usado no sentido de um processo em movimento que é flutuante e também faz referência a diferentes culturas e perspectivas, que reforçam e destacam a estrutura das associações livres que os contém. Consequentemente, esta potencialidade também terá um efeito sobre os espectadores, envolvendo-os em novos relacionamentos com a 'dança' através desta abordagem.

Antes da década de 1990, o termo somática já tinha ganhado reconhecimento generalizado, coincidindo com um ressurgimento do interesse filosófico e científico no papel do campo da somática no pensamento e da experiência humana. Tanto os/as teóricos/as das mídias como as/os artistas da dança que trabalham com o digital também começaram a considerar noções somáticas de corporização (embodiment) e estudos da percepção (DAVIDSON, 2013). Seja na parte prática ou na análise teórica durante o processo de pesquisa-criação, a integração da somática como um meio de reavaliar as relações entre dança e tecnologia, constitui não só uma contribuição para a compreensão desta relação em particular, mas também nos informa sobre as potencialidades da evolução tecnológica em geral (LEROI-GOURHAN [1945] 1973). Além disso, proporciona uma perspectiva diferente aos paradigmas estéticos, filosóficos e científicos associados à tecnologia. $\mathrm{Na}$ visão de Davidson, "desde o ponto de vista da pesquisa prática, [novos rumos na pesquisa sobre a relação entre a somática e a tecnologia] confirmam o papel do corpo como um local privilegiado na construção do conhecimento, e o entrosamento inegável dos sentidos com a 
(e na) experiência mediada" (DAVIDSON, 2013: 11). Priorizando a noção de conhecimento corporal e com "o entrosamento dos sentidos com / na experiência mediada', estas posições recentes sobre o papel da somática testemunham o compromisso de certos artistas de experimentar com diferentes formas de mediação corporizada (embodied mediation) e novas interpretações da corporização (embodiment).

\section{I.1 A inteligência do corpo: para uma abordagem multi-sensorial e multimodal}

Um dos princípios fundadores do projeto como um todo, pode ser encontrado na noção de inteligências complementares (GARDNER, [1983] 2006) e, mais especificamente, na revalorização e re-priorização da inteligência corporal-cinestésica ${ }^{3}$. Da mesma forma, esta abordagem se situa contra o pensamento ocidental clássico, que é predominantemente objetivo, e também contra um legado de metodologias existentes nas artes, que eu vejo como problemático (LAFLAMME, 2009). Uma relação direta pode ser estabelecida entre formas corporais / cinestésicas de inteligência e práticas somáticas. A relevância da teoria das inteligências complementares de Gardner para a minha metodologia está também relacionada com o fato de que diferencia a inteligência em "modalidades" específicas aprendizagem, sensorial- ao invés de abordar a inteligência como uma capacidade única e geral. Esta abordagem "capacita os/as alunos/as" e não os /as limita a um único modo de aprendizagem (GARDNER, [1983] 2006). Na dança, uma modalidade de aprendizagem podería envolver sensorialidade ou movimento, em oposição à língua ou à lógica. Estes resultados também têm implicações a nível teórico, no sentido de que diferentes formas de inteligência podem contribuir para uma perspectiva multimodal.

\section{I.1.1 A inteligência somática e a capacidade de auto-organização corporal}

A inteligência somática pode ser considerada como outra forma de inteligência corporal (Davidson, 2013; Leste, 2013; Brannigan, 2011). As práticas somáticas têm como objetivo desenvolver o auto-conhecimento, o auto-controle e uma aplicação ativa da vontade aos processos de crescimento e desenvolvimento (JUHAN, 1998). Para os/as praticantes de dança, a inteligência somática constitui uma forma de conhecimento corporizado, que também pode ser descrita como uma habilidade aumentada para a deteç̧ão, a percepção e a busca de interrelações. Os três elementos fundamentais subjacentes aos princípios da educação somática são Sintonia Sensorial, Novos Contextos de Aprendizagem e Repouso Aumentado. Estes elementos contribuem para despertar a autonomia, especialmente através de concentrar a atenção em estímulos sensoriais do corpo, assim como sobre a respiração, tensão muscular e contato corporal com o chão, partes do corpo próprio ou de outra pessoa. Na minha pesquisa prática, isso corresponde a trabalhar com bailarinos/as, a

\footnotetext{
${ }^{3}$ A inteligência cinestésica foi identificada e reconhecida nas ciências por Gardner, Howard e Perkins (1974), Gardner e Wolf (1983), Walter e Gardner (1985), Chomsky (1980), Fodor (1983), Brown, Collins e Duguid (1989), Laves (1988), Rogoff (1982) e Scribner (1986). Veja também: Gardner, Howard e Hatch, Thomas, "Multiple Inteligences, Go to School. Education Implications of the Theory of Multiple Inteligences, "Educational Research (eds. Carolyn D. Herrington e Vivian L. Gadsden, vol. 18, n. 8, Novembro de 1989, Califórnia, E.U.A: SAGE Journals: 4-10. No campo da dança, estudiosos como Fraleigh ([1987] 1991), Laban (2007), Bernard (2001), Branningan (2011), Oriente (2013) e Davidson (2013), entre muitos outros, têm relacionado a inteligência cinestésica tanto à dança como às práticas somáticas.
} 
fim de desenvolver um estado de presença total, receptividade e consciência dos momentos quando o movimento toma forma. Também corresponde à criação de intervalos entre a consciência da sensação e movimento para que possam explorar, onde estava a sua atenção e estar cientes das informações sensoriais - tanto em um estado de imobilidade ou quando executam os movimentos. A sintonia sensorial é, portanto, uma ferramenta muito interessante para coreógrafos uma vez que favorece:

[...] a percepção sensorial (prestando atenção à detecção) em detrimento da ação motora (fazer). [...] Ao dar-se aos bailarinos a oportunidade de explorar -e dar sentido- às sensações internas (sinais neurais), se promove a "autoridade sensorial ", uma base para a auto-orientação e controle. A autoridade sensorial promove a autonomia do movimento (a capacidade de se auto-organizar internamente 0 movimento) diferindo das referências externas geralmente usadas para aprender dança [...] a sensibilização cinestésica funciona em grande parte como um potente agente de mudança -um meio poderoso de alterar hábito. (BATSON, 2009)

O princípio do descanso aumentado serviu como um meio criativo para integrar a exploração do movimento, propondo fases alternadas entre repouso e atividade "projetadas para que o sistema nervoso tivesse tempo para o processamento e a integração da informação e que os sistemas fisiológicos pudessem se recuperar" (BATSON, 2009). Esta estratégia de recuperação física também permite a programação motora (ou reprogramação). Como Glenna Batson, professor norte-americano e experimentado praticante de técnicas somáticas disse "os períodos de descanso ajudam a consolidar a memória (você vai se lembrar de quando você aprendeu) e melhoram a recuperação motora (você vai se lembrar rapidamente quando você precisar" (BATSON, 2009). Além disso, o reposo aumentado auxilia os/as dançarinos/as a recordar sensações específicas ou "conhecidas" como referências das que partir para recriar um movimento particular ou um estado corporal, e para estabelecer ligações intercorporais. Por último, melhora os resultados, permitindo aos dançarinos avançar na sua exploração da percepção sensorial e descobrir, entre outras coisas, um maior potencial de mobilidade.

Um aspecto final da inteligência somática que foi particularmente útil no contexto da minha pesquisa prática é a capacidade do corpo para a "auto-organização". Com base em modalidades de aprendizagem que passam pelo aspecto sensorial, esta capacidade está ligada ao princípio somático da harmonização ou sintonia sensorial. A capacidade do corpo de auto-organização pode, assim, ser considerada uma outra forma de inteligência física. $\mathrm{Na}$ dança, isso corresponde a uma organização do movimento através de/ por si só. Em primeiro lugar 0 aspecto fisiológico envolve elementos como memória muscular, distribuição de peso, equilíbrio, coordenação, et caetera. Em segundo lugar, o aspecto perceptual, se sustenta sobre a receptividade sensorial e a percepção. Em terceiro lugar, no contexto da minha pesquisa, isso inclui o desenvolvimento da consciência das novas sensações dentro de um novo ambiente criativo e de aprendizagem. Assim, tendo em conta as posições de Rudolf Laban (2007), influente teórico da dança do século XX, e de Michel Bernard (2001), eu avanço a ideia da dança como uma reorganização sensorial e perceptiva do corpo.

\section{I.1.2 O corpo carnal, estratégias de desestabilização e romper a hierarquia dos sentidos}


Como parte de minha pesquisa prática, todas as observações acima serviram para orientar o processo criativo, particularmente no que diz respeito ao desenvolvimento do que chamo de estratégias de "desestabilização sensório-perceptivas" e uma "ruptura da hierarquia dos sentidos" (CHOINIERE, 2013, 2014, 2015). Estas estratégias foram destinadas a "ativação" do corpo físico no seu contato direto e experiência da tecnologia. Neste contexto particular, o corpo constitui uma condição permanente para a experiência e a referência, pois é por meio da percepção corporizada que o/a dançarino/a descobre o mundo -aqui, o ambiente tecnológico ou mediado- assim como os outros e ele/ela mesma através da sensação. A experiência perceptiva do/da artista inevitavelmente implica fisicalidade (corporalidade), bem como corporeidade (o meio pelo qual ele/ela descobre e se apropria de novas informações, mudanças de estado, e as sensações em seu espaço interno e no ambiente circundante onde atua). No decurso destas experiências e contato com a tecnologia, 0 conceito de um "corpo carnal" surgiu e incorporou uma reconfiguração sensório-perceptivo do corpo físico, com consequências e modificações subsequentes para a corporalidade, que, por sua vez, gerou uma corporeidade particular e modificada.

O corpo carnal pode ser descrito como um lugar de encontro, que cria uma sensação de co-pertencer a/em um mundo compartilhado. A "carne" constitutiva do/da bailarino/a não é considerada como um obstáculo, mas sim como um lugar de encontro, porque a "carne" é 0 elemento que permite uma transdução entre corpos -físico e mediado- e funda a própria dimensão da experiência. Reconfigurado, sob a ação da tecnologia, o corpo carnal torna-se o ponto de encontro do corpo físico e uma potencialidade capaz de gerar uma dinâmica de transformação (CHOINIERE, 2013, 2014, 2015; PITOZZI, 2009, 2010a, 2013a, 2015). A corporeidade resultante é a de um estado de fusão, uma alteração de forças presentes, que no meu processo artístico, é produzida por meio de estratégias de desestabilização sensório-perceptiva que diz respeito tanto ao corpo físico coletivo e como ao corpo mediado. Estas estratégias provocam uma notável reorganização da interioridade do corpo - uma interioridade modificada - e, por sua vez, poderiam ser interpretadas como a posta em valor de um corpo carnal do século XXI.

Voltando ao contexto das minhas experiências em que a tecnologia é vista como uma forma de fisicalidade que reorganiza a percepção -fazendo-a mais complexa (CHOINIERE, $2013,2015)$ e modifica a fisicalidade- o processo criativo levou-me a investir em um modo sinestésico de compor. Através da sua complexidade as estratégias de desestabilização que pus em prática foram concebidas como um meio de provocar e produzir estes novos modos de percepção. Especificamente, este processo envolveu uma desestruturação dos códigos corporais e perceptivos que, parafraseando Berthoz, "cada sentido de-compõe a realidade sensivel em componentes que são posteriormente agregados, relacionados" (BERTHOZ, 1997: 288, grifo do autor). Mais concretamente, a pesquisa prática desenvolveu um "corpo coletivo" composto por cinco bailarinos em evolução como uma massa fortemente unida de corpos em um estado de auto-organização. Nesta forma coletiva, o corpo se organiza em torno de sensação e a auto-organização é também usada como um meio para atingir um estado de transe, igualmente produzido por uma perda de referências. É precisamente esta perda de referências que permite a criação de um espaço físico e psicológico em fluxo como uma forma de intersubjetividade corpórea ou intercorporeidade, ou um estado de dissolução das fronteiras psicofísicas, que Suely Rolnik 
(2006) foi capaz de identificar. Assim, esta pesquisa envolve um distanciamento das codificações estabelecidas.

\section{I.1.2.1 "0 corpo coletivo": descrição esquemática e fases de experimentação}

0 "corpo coletivo" foi concebido como uma entidade híbrida: uma escultura tridimensional em movimento com cinco dançarinos/as parcialmente nus/nuas que estão em contato quase constante. Esta forma tem como referência a sensação táctil, cinestésica e proprioceptiva, bem como uma dinâmica criativa enraizada no experiencial, no evolutivo e no transversal: uma forma perceptual em evolução, com reconfigurações sensórioperceptivas contínuas. 0 tato, como a estratégia de pesquisa principal, foi utilizado como um meio para interromper uma lógica de sensação baseada somente em esquemas sensório-motores, ou na separação de interior / exterior, passivo / ativo, - o que consequentemente traz a dissolução da relação entre o objeto e o sujeito. Ao corpo físico coletivo também foi atribuída uma dimensão sonora. Aqui, a partitura sonora (soundscore) é produzida em tempo real pelos/pelas dançarinos/as e está intimamente relacionada com as diferentes dinâmicas de seu movimento. 0 corpo sonoro também tem a particularidade de gerar uma dinâmica sonora coletiva, constituindo um corpo coletivo sonoro cuja entidade se assemelha a um "sexto bailarino", com sua específica dinâmica, temporalidade, e relação com o espaço.

Para estabelecer a ligação entre o corpo físico coletivo e o corpo sonoro coletivo foram empregados dispositivos tecnológicos, destinados a permanecer invisíveis. Inicialmente se tratava de microfones sem fio usados pelos dançarinos sob turbantes negros. Posteriormente, um programa de software original foi criado para espacializar 0 som. 0 som que emanava dos dançarinos era capturado pelos microfones e, a continuação, era transmitido ao computador para processamento e espacialização dos dados sonoros em relação ao espaço performativo. Além disso, os sons e gestos produzidos pelos artistas individualmente retornavam, como manifestações mediadas pelo corpo, estendendo-se aos outros artistas, de modo a intensificar, complexificar e definir os cinco corpos como um corpo sonoro coletivo único.

Essas sobreposições sensoriais têm como referência a teoria do quiasma intersensorial de Merleau-Ponty (1945; BERNARD, 1993). Com base nos conceitos de corporeidade e intercorporeidade já delineadas, este fenómeno, na minha pesquisa prática, funciona como o equivalente a uma abertura ontológica do corpo físico, que também encontra ressonância na noção de carne de Merleau-Ponty: através do "corpo próprio" vivido e da cinestésia. As mesmas sensações que nos informam sobre o corpo e o movimento são proprioceptivas e, na maioria das vezes, estão associadas com o sentido cinestésico. A propiocepção é o sentido que faz um retorno sobre o "próprio corpo", fornece um feedback importante já delineado no caso de tato e também no princípio da reversibilidade do conceito de primeiro quiasma de Merleau-Ponty (1945; BERNARD, 1993 ). Ou o que Fígols aponta como sendo "um sentido do meio": por exemplo, como a propensão particular do tato para conectar a interioridade e a exterioridade, a passividade e a atividade, o movimento e a percepção (FIGOLS, 2000). E, como Després também observa, "o sentido cinestésico refere-se a uma 
sensação de corpo, seus movimentos internos e externos, a sensação do que está em movimento, do que está vivo" (DESPRÉS, 1998: 459).

Retornando à análise da organização espacial nestas experiências, a cenografia foi concebida para estabelecer três espaços circulares concêntricos de expansão para 0 exterior. O primeiro círculo, de seis metros de diâmetro e posicionado centralmente, constitui um espaço de atuação em que os bailarinos se movem. O público está posicionado em torno deste círculo em estreita proximidade com os dançarinos (aproximadamente $0,5 \mathrm{~m}$.). 0 terceiro círculo é exterior e está formado por cinco altofalantes que abrangem todo o espaço de atuação e fazem parte do design da espacialização sonora (quatro alto-falantes ao redor do espaço de atuação - incluindo espectadores - e um no centro do teto). A extrema proximidade dos espectadores e dos dançarinos fez parte de uma estratégia consciente de desestabilização sensorial e perceptiva. Com este hiper-proximidade, eu quis provocar um efeito hipnótico para os espectadores através de confrontá-los com uma forma complexa de carne composta dos corpos dos bailarinos, que ao se tornar audível, também se transformava numa massa de carne que cantava, murmurava e gemia. A proximidade de corpos nus dos dançarinos provoca uma primeira fase de desorientação, uma de-hierarquização, porque o público se encontra a si mesmo na carne. A de-hierarquização- aqui, do corpo - é também expressada pelo fato de que as partes do corpo não desempenham as suas funções normais ou convencionais. Por exemplo, as pernas desempenham o papel de braços, ou se multiplicam, como no trabalho do pintor e escultor alemão Hans Bellmer ${ }^{4}$ (1902-1975) ou na coreografia Pezzo o $(d u e)^{5}$ da dançarina-coreógrafa italiana Maria Donata d'Urso. Ambos artistas foram fontes de inspiração para o desenvolvimento do projeto desde sua terceira fase em diante.

A segunda fase da desorientação do público ocorre como resultado da imersão em uma forma sonora viva em movimento e produzida em tempo real pelos cinco dançarinos, intensificada através da proximidade, 0 que Ihes tira das suas referências analíticas normais e do mecanismo de distanciamento do espectador: os espectadores ouvem intimamente esta massa de carne. Os espectadores encontram-se na forma, são confrontados com algo extremamente íntimo, e, ao mesmo tempo, imersos no som que se move em torno deles e penetra o seu espaço. Estas duas formas -a carne dos cinco corpos entrelaçados e o corpo sonoro criadas em tempo real- confrontam os espectadores, ofuscando códigos, e provocando um desnorteamento.

O trabalho foi concebido para encenar a presença e a "carne" dessa massa humana tanto na sua dimensão material como na interconectada. É uma versão encarnada da visão de Merleau-Ponty do mundo experimentado como / na carne (a carne do mundo/ la chair du monde), integrando "o próprio corpo" no princípio da coexistência. Esta dinâmica de intercorporeidade é central para a minha pesquisa prática, com o princípio da coexistência dando origem a um entrelaçamento de ser e mundo, uma interpenetração do interior e do exterior. Uma viagem poética dentro de uma forma hiper-íntima e de um erotismo

4 Ver https://www.artsy.net/artist/hans-bellmer http://www.moma.org/collection/artists/452 (acessado 31 de Dezembro de 2015).

${ }_{5}^{5}$ Maria Donata d'Urso, vídeo Pezzo O (due), 1999. Ver http://vimeo.com/20828755 (accessado 18 de Dezembre de 2013). 
escultural, esta criação é um hino à vida, ao feminino e à beleza. É um reflexo da pesquisa de Merleau-Ponty sobre a sensorialidade, percepção e a capacidade de comunicar com os outros de forma intersubjetiva e empática. Ele também destaca qualidades e um modus operandi refletindo o que Després observa como "[...] a sensação do Outro e a relação com o Outro implica um contágio. 0 contágio não é imitação, mas [sim] uma montagem de elementos que, ainda mantendo-se diferentes, se impregnam mutuamente com as suas respectivas consistências" (DESPRÉS, 1998: 394). A minha pesquisa prática propõe, assim, uma reflexão sobre o orgiástico num sentido mitológico e Nietzchiano do termo: uma experiência do corpo em movimento para criar formas diferentes que resultam de um desnorteamento.

\section{I.1.2.2. Etapas do processo criativo}

O corpo coletivo foi testado como uma forma performativa emergente formada por uma experiência física da tecnologia vivida como um entorno tecnológico. Nas experiências que levaram ao desenvolvimento do corpo coletivo, os princípios de auto-organização, repouso augmented (augmented rest), e Contexto de Aprendizagem Novel (Novel Learning Context), que eu tinha testado no meu próprio corpo em criações anteriores, foram comunicados e desenvolvidos com os dançarinos. Ao criar as condições para o foco no feedback sensorial, em primeiro lugar através de pequenos movimentos associados à respiração, e depois através do desenvolvimento de movimentos maiores que podíam estar ligados a esta última, os dançarinos começaram a identificar graus de contração muscular que thes permitem executar o movimento com maior consciência de sensação. Estes exercícios fizeram parte das minhas estratégias de desestabilização sensorial e perceptiva: através deles, os/as dançarinos/as foram capazes de descobrir sensações diferentes associadas com a exploração do movimento, e, posteriormente, construir novas referências com base nas sensações que acabam de descobrir, novos movimentos até então desconhecidos, inexplorados ou, alternativamente, reproduzir o movimento, referindo-se a sensações recentes. Como Batson argumenta:

[0] propósito de tal "playground" do movimento é perturbar os padrões de movimento habituais enterrados no esquema corporal. À medida em que os velhos padrões habituais começam a se dissolver num entorno de conforto e segurança, tornam-se possiveis novas opções para a coordenação (BATSON , 2009).

A criação de formas novas e inusuais de movimento evita o que Hubert Godard 6 -cofundador da Departement de Dance, Université Paris 8, e grande autoridade na análise do movimento-, chama padrões de movimento recorrentes ou uma forma de "nevrosis coreográfica" (KUYPERS, 2006). Esta "nevrosis" pode ser descrita, também, como dificuldade para abrir mão de hábitos gestuais (QUINZ \& MENICACCI , 2006; PITOZZI , $2010 \mathrm{~b}$ ) . Este " nevrosis " caso contrário pode ser descrito como dificuldade em abrir mão de hábitos gestuais. Na pesquisa prática, as estratégias de desestabilização sensório-

${ }^{6}$ Simultâneamente desenvolvendo a carreira am dança clássica e contemporânea, Hubert Godart dirigiu a sua pesquisa sobre as técnicas somáticas. Isto lhe levou a pesquisar os dominios da reabilitação funcional, biomecânica e a função do sistema nervoso na motricidade. Desde 1988 vem trabalhando regularmente em hospitais como pesquisador para o Instituto Nacional do Câncer em Milão, Itália. Em 1990, co-fundou o Departamento de Dança da Univeristé Paris 8, junto com Michel Bernard, onde ensina análise do movimento e pesquisa sobre a percepção do corpo 'desde dentro' (VIGARELLO, 2006; SUQUET, 2006; PITOZZI, 2014). A amplitude das suas referências no ensino vai da biomecânica às diferentes técnicas corporais e à estética da expressão humana. 
perceptivo tiveram a intenção de provocar o surgimento de uma nova potencialidade na experiência do movimento, dos estados corporais, da projeção cênica, e da intercorporeidade.

Em conclusão, um dos objetivos desta pesquisa prática foi a criação de uma série de condições para aumentar o âmbito da sensibilização e ação dos dançarinos (assim como a minha) para abraçar a tecnologia como uma físicalidade, e, por extensão, viver uma experiência de incorporação diferente e enriquecedora. A experiência imediata e não discursiva que é vivida através de princípios somáticos pode levar a "um nexo transacional de energias que interagem ligando o ser encarnado e seu mundo circundantes" (SHUSTERMAN, 2002: 220). Proponho que este tipo de experimentação pode servir como um exemplo de novos encontros entre o somático e a tecnologia que os profissionais somáticos como Shusterman (2008) ou Batson (2009) podem ter intuído sem saber as formas futuras que a somática podería assumir.

Um último ponto importante -na verdade fundamental-. 0 treinamento físico é absolutamente necessário para desenvolver a inteligência somático/ cinestésica. Esta não pode ser adquirida por meio de simulação virtual (GARDNER [ 1983 ] 2006). E é aqui -em virtude de uma necessidade imperiosa de abordar o corpo fenomênico e, por extensão, de repriorizar as inteligências corporais cinestésicas- que a principal articulação do trabalho prático pode ser distinguida em dois eixos no meu método (CHOINIERE, DAVIDSON \& PITOZZI, en cours), e na introdução dos elementos constitutivos da metodologia de experimentação: (1) a experiência proprioceptiva como orientação para a pesquisa sobre 0 corpo; e (2) a importância do contato físico diário com a tecnologia durante as experiências práticas.

\section{I.2 A "coexistência" do físico e mediado: a "carne" como um lugar da corporeidade emergente}

A pesquisa envolvendo a aplicação do conhecimento somático a entornos tecnológicos ainda está em seus estágios iniciais e é interessante analisar -mesmo quando ainda são poucos os artistas que realmente examinam estas questões em profundidade- a multiplicidade de direções diferentes que este tipo de pesquisa pode tomar. Assim, com a hibridação que ocorre no desenvolvimento de novas potencialidades corporais e corporeidades, o trabalho de artistas da dança que investem em tecnologia "se enfoca a um status de tipo experimentador, um pesquisador, no laboratório de experiência corporal" (ROUX, 2007: 121). A corporeidade performativa da dança que envolve tecnologia não tem como intenção o desenvolvimento virtuoso ou místico, mas sim formar "a matéria a ser redescoberta através de um modo de pensar consciente sobre o ser" (ROUX, 2007: 192). 0 processo ativo e os efeitos da interação do artista com as tecnologias digitais não agem entre os corpos, mas sim com os corpos, no corpo, para o corpo. Na sua capacidade de transdução, o meio da carne é mais do que um material de suporte. É o lugar de uma proposta combinatória dos 'possíveis'. Muito mais do que um material, é a forma que tece a co-pertença no mesmo mundo. Os entornos tecnológicos introduzidos por artistas se tornam um espaço performativo para uma autotransformação potencial, permitindo também aos artistas redefinir a natureza do corpo, seus contornos e limites. Esta é a essência das explorações da corporeidade. 
As reflexões teóricas sobre essas mudanças que provem do ponto de vista dos praticantesteóricos da somática, que mostram interesse na questão da somática e da tecnologia, também podem ser-nos muito úteis. $O$ trabalho e os escritos de Cecília de Lima, uma bailarina-coreógrafa e pesquisadora do Instituto de Etnomusicologia, Centro de Estudos em Música e Dança, em Lisboa, assim como de Malaika Sarco-Thomas, artista e encargada do curso da Universidade de Falmouth, U.K., e de Ali Oriente, artista e professor da Universidade de Otago, Nova Zelândia, podem ser citados como exemplos. De Lima explora o tema de uma intensificação da consciência proprioceptiva, que ela vê como sendo fundamental para uma forma incorporada de se relacionar-se com o mundo e dar-lhe sentido (2013: 18). Ela faz isso explorando a noção de conhecimento corporeizado (embodied knowledge) como uma resposta à tecnologia que pode gerar uma compreensão alternativa e experimental da realidade e das transformações de natureza somática. Seu lugar de experimentação é o seu próprio corpo como um lugar para o desenvolvimento de pesquisa e para uma compreensão da consciência proprioceptiva.

Varias características distinguem a minha pesquisa da de outros coreógrafos e teóricos que olham a questão do corpo performativo e sua relação com a tecnologia. A primeira é que ela não adota uma interpretação filosófica da tecnologia -tais como dispositivos tecnológicos e próteses- como "extensões". Esta é entendida como uma posição materialista onde o corpo é considerado "obsoleto", não suficientemente eficaz para a evolução, o que o torna assim substituível pela tecnologia (CHOINIERE, 2014; KOESTLER \& SMYTHIES, [1968] 1972; SIMONDON, [1958, 1969, 1989] 2001). A segunda é que não adere à teoria de Deleuze e Guattari de rizomas - uma variação sobre a ideia de extensão. A terceira é que tampouco abraça uma visão pós-humana e pós-fenomenológica do corpo (IHDE, 2009; MISI \& PIMENTEL, 2016). E por último, não adota um ponto de vista estético nem linguístico, que consideram o corpo como algo "legível" (o processo de composição do movimento mais como escritura que como experiência proprioceptiva vivida) como por exemplo no caso de Lima (2013). Minha abordagem não assume uma perspectiva de terceira pessoa sobre o que é externo ou do meio ambiente. Compreende-lo desde um ponto interno, desde um ponto de vista sensorial, a partir de uma perspectiva de primeira pessoa. Esta perspectiva também contribui para a minha compreensão da intercorporeidade porque o que está "fora", na verdade, constitui parte de nossa interioridade sensorial e perceptiva. Este entendimento contribui para uma compreensão do corpo mediado à luz da experiência fenomenológica que pode enriquecer a expressão performativa. Por sua vez, uma mediação fenomênica, considerada como uma outra forma de corporeização, participa neste enriquecimento.

Eu gostaria de compartilhar alguns dos pensamentos de Pitozzi -um teórico que experimentou pessoalmente esta pesquisa-criação- tanto sobre a sua dimensão multisensorial como sobre a sua natureza multi-modal, pois, de acordo com ele, estas estratégias provocam uma reorganização perceptual. Ao observar e vivenciar a influência entre artista e espectador, Pitozzi testemunha o efeito sinestésico produzido, que lembra 0 efeito da segunda chiasma intersensorial de Merleau-Ponty e que também reflete a terceira chiasma para-sensorial e o fenômeno da intersubjetividade sobre os quais Merleau-Ponty afirma: 
Podemos falar, portanto, de um aspecto tátil do trabalho do som. O som elaborado de acordo com a estratégia de moleculerisação ${ }^{7}$ e disposição espacial opera com frequências muito altas e muito baixas e tende a articular-se através de um comprimento de onda contínua que estabelece um relacionamento constante com os corpos que estão escutando. Esta proximidade entre o corpo do performer (visivel e auditivamente), contudo, não levar o público a uma situação de som extremo: a comunicação passa por causa dos diferentes níveis cromáticos de som, diferentes níveis de vibração. $O$ espectador é, portanto, imerso na vibração contínua, de um segmento de som como um gesto, e é nessa escala de variações que a atenção deve situar-se. 0 que se afirma é que os parâmetros que o espectador deve colocar em ação não são simplesmente óptico-visuais ou auditiva-sonoros, mas o processo de composição da coreógrafa Isabelle Choiniere requer um olhar e modo de escuta sinestésicos, uma relação contemporânea e ativa entre os sentidos. É necessário configurar os corpos de outra maneira, a fim de receber esses sinais. Não é 0 suficiente ter olhos para ver 0 invisível ou ter ouvidos para a ouvir 0 inaudivel (PITOZZI, 2010b, tradução original).

De acordo com a abordagem que este capítulo perfilou, a tecnologia é um elemento desestabilizador que cria uma nova organização sensorial, na qual a interioridade torna-se mediada e, assim, cria uma nova referência experiencial, uma nova " realidade" para 0 performer e o espectador. Esta é, em primeiro lugar, uma realidade vivida e sentida pelo corpo (FIGOLS, 2000; KUYPERS, 2009; Godard 1993, citado por SUQUET, 2006). É um estado de reorganização que está em constante movimento. Outra característica desta abordagem é destacada por Davidson ${ }^{8}$ :

[Choiniere é] uma das raras coreógrafas que vem trabalhando exclusivamente com novas tecnologias desde o início de sua carreira. [...] En todas as suas criações, a desestabilização produzida por um agente tecnológico externo, pelo contrário, apresenta um meio de transformar e " reorganizar" a sensorialidade e a percepção do performer. A consciência interna torna-se hibrida, pois a percepção do que é mediado se entrelaça com as sensações do corpo orgânico, provocando mudanças na sensorialidade, maior sensibilidade (awareness) e um novo modo de comportamento performático. Neste sentido, Choiniere vê a tecnologia como uma ferramenta potencial para a auto -transformação. (DAVIDSON, 2013: 10)

Como resultado, acredito que, por participar da experiência fenomenológica do corpo performativo, essa abordagem pode levar a uma compreensão do corpo mediado/mediatizado. Por sua vez, outra forma de corporeização caracterizada por esse enriquecimento -tornada possível pelo meu processo experimental, simultaneamente, envolve e estimula a evolução da corporeidade.

\section{Referências}

BATSON, Glenna. "Somatic studies and dance." International Association for Dance Medicine and $\begin{array}{lllll}\text { Science, } & (17 & \text { September } & \text { 2009). } & \text { Disponível }\end{array}$

\footnotetext{
${ }^{7}$ Quando Pitozzi (2010b) fala da molecularização, se refere ao corpo sonoro que criei, e assim ao corpo carnal que é molecuralizado e recomposto como as partículas vibratorias de natureza auditiva.

${ }^{8}$ Davidson experimentou a pesquisa-criação Flesh Waves em novembro de 2013 na Alemanha durante

0 evento Metacorpo.
} 
http://c.ymcdn.com/sites/www.iadms.org/resource/resmgr/resource_papers/somatic_studies.pdf (consultado 15 de Outubro de 2014).

BENKIRANE, Réda. La Complexité, vertiges et promesses. Dix-huit histoires de sciences. Paris: Le Pommier, 2002.

BERNARD, Michel. "Sens et fiction ou les effets étranges des trois chiasmes sensoriels". Nouvelles de danse, Dossier: À l'écoute du corps, no. 17 (Outubro, 1993), Bruxelles: Contredanse: 56-64.

De la création chorégraphique. France: Edition Centre national de la danse, Collection Recherches, 2001.

BERTHOZ, Alain. Le sens du mouvement. Paris: Editions Odile Jacob, 1997.

BLAY, Michel, ed. Dictionnaire des concepts philosophiques. Paris: Larousse - CNRS Editions, Collection-In Extenso, 2006.

BOISCLAIR, Louise. "Isabelle Choinière de Corps Indice; autour des Demoiselles d'Avignon". In Inter Art Actuel, no. 98 (2007), Montreal: Inter art publishing: 52-56.

BRANNIGAN, Erin. Dance Film: Choreography and the Moving Image. New York: Oxford University Press Inc, 2011.

CHOINIERE, Isabelle. "For a methodology of transformation: At the crossing of the somatic and the technology, to become other..." Journal of Dance \& Somatic Practices, Special isssue: Somatics and technology, edited by Andrea Davidson and Sarah Rubidge, vol. 5, issue 1 (2013). Bristol: Intellect Press: $95-112$.

"The interval as a new approach to interfaces: Toward a cognitive and aesthetic paradigm of communication in the performing arts." In The Point of Being, edited by Derrick de Kerckhove and Cristina Miranda de Almeida, 103-45. Newcastle-upon-Tyne: Cambridge Scholar Publishing, 2014

_ "The complexification of self: At the crossroads of concepts of flux and 'living at risk'." Technoetic Arts: A Journal of Speculative Research, Special isssue: Moistmedia, edited by Isabelle Choinière (Lead), Cristina Miranda de Almeida, Carlos Augusto Moreira da Nóbrega and Maria Luiza P. Guimarães Fragoso, vol. 13, no. 1+2 (2015). Bristol: Intellect Limited: 25-44.

CHOINIĖRE, I., DAVIDSON, A. \& PITOZZI, E. The prism of the senses: New "realities" of the body in contemporary performance (em processo).

DAVIDSON, Andrea. "Somatics: An orchid in the land of technology." Journal of Dance \& Somatic Practices, Special isssue: Somatics and technology, edited by Andrea Davidson and Sarah Rubidge, vol. 5, issue 1 (2013). Bristol: Intellect Press: 3-15.

"Isabelle Choinière: Corps Médiatisés". In Parcours L'Informateur des arts, no. 86 (December 2015), Montreal: Les Editions Trajet Inc.: 58-59.

DESPRES, Aurore. Travail des sensations dans la pratique de la danse contemporaire. Logique du geste esthétique. Ph.D. Thesis Nouveau Régime Esthétique, Sciences et Technologies des Arts (Option Danse). Paris: Université Paris VIII - Saint-Denis, 1998.

DELEUZE, Gilles; GUATTARI, Felix. Milles Plateaux; Capitalisme et schizophrénie 2. Paris: Les Éditions de Minuit, Collection Critique, 1980.

FIGOLS, Florence. Parcours sensible d'un processus de composition chorégraphique [microforme]: sensation, improvisation, interprétation. MA. Thesis in dance. Montreal: Université du Québec à Montréal, 2000.

FRALEIGH, Sondra Horton (1996). Dance and Lived Body. Pittsburgh: University of Pittsburgh Press. Publicado originalmente em 1987.

GARDNER, Howard, (2006). Frame of Minds: The Theory of Multiples Intelligences. Cambridge, MA: Edition Gardner. Publicado originalmente em 1983.

HACKNEY, Peggy. Making Connections. Total Body Integration Through Bartenieff Fundamentals, Amsterdam: Gordon and Breach Publishers, 1998.

IHDE, Don. Postphenomenology and Technoscience. The Peking University Lectures, Albany: State University of New York Press, 2009.

KOESTLER, Arthur \& SMYTHIES, J.R., eds., (1972). Beyond reductionism, new perspectives in the life of sciences: Proceedings of the Alpbach Symposium 1968. Boston: Beacon Press. Publicado originalmente em 1968.

KOZEL, Susan. Closer: Performance, Technologies, Phenomenology. Cambridge, MA: MIT Press, 2007. 
KUYPERS, Patricia. "Des trous noirs; Un entretien avec Hubert Godard Bruxelles". In Nouvelles de Danse, no. 53, Scientifiquement Danse; Quand la danse puise aux sciences et réciproquement, 5675. Bruxelles: Contredanse, 2006.

LABAN, Rudolf Von. La maîtrise du mouvement. France: Edition Acte sud, 2007.

LAFLAMME, Yvonne. "La science de l'art/l'art de la science: une synergie propre à un nouvel esprit scientifique en recherche création." In La recherche création; pour une compréhension de la recherche en pratique artistique, edited by Pierre Gosselin and Éric Le Coguiec, 65-76. Quebec: Presses de l'Université du Québec, 2009.

LEROI-GOURHAN, André. L'homme et la matière. Évolution et techniques. Paris: Editions Albin Michel, Collection Sciences d'aujourd'hui, no.I. Publicado originalmente em 1943, 1971.

LEROI-GOURHAN, André. Milieu et techniques: Évolution et techniques. Paris: Editions Albin Michel, Collection Sciences d'aujourd'hui, no.II. Publicado originalmente em 1945, 1973.

LIMA, Cecilia. "Trans-meaning - Dance as an embodied technology of perception." Journal of Dance \& Somatic Practices, Special isssue: Somatics and technology, edited by Andrea Davidson and Sarah Rubidge, vol. 5, issue 1 (2013). Bristol: Intellect Press: 17-30.

MERLEAU-PONTY, Maurice. Phénoménologie de la perception. Paris: Gallimard, 1945.

MISI, Mirella \& PIMENTEL, Ludmila. "Phenomenological and Post-phenomenological perspectives in mediadance." In The Oxford Handbook of Screendance Studies, edited by Douglas Rosemberg. Oxford: Oxford University Press, 2016.

MORAN, Dermot. Introduction to Phenomenology. London and New York: Routledge, 2000.

MORIN, Edgar. La méthode. Tome 1. La nature de la nature. Paris: Éditions du Seuil, 1977.

- Pour sortir du vingtième siècle. Collection 90, Paris: Éditions Fernand Nathan, 1981.

Perrin, Julie. "Les corporéités dispersives du champ chorégraphique: Odile Duboc, Maria Donata d'Urso, Julie Nioche." International Colloquium proceedings Projections: des organes hors du corps, edited by $H$. Marchal and A. Simon, (13-14 October 2008). Paris: 101-07. Available at http://www.epistemocritique.org//MG/pdf/ProjectionsPerrin.pdf (consultado em 9 de Junho de 2010).

Pitozzi, Enrico. "Espace stéréoscopique pour corps sonore." Archée, (December 2009). Available at http://archee.qc.cal

"Étendre la peau; Scène, perception, dispositifs technologiques." In Ensemble ailleurs/Together elsewhere, edited by Louise Poissant and Pierre Tremblay, 321-40. Quebec: Presses de l'Université du Québec, Collection Esthétique des arts médiatiques, 2010a.

"Corpo sonoro collettivo. Verso una tattilita uditiva"/ "A collective resounding body: Aiming towards an auditory tactility." Digimag, no. 51, (2010b).

—_ "Sismographies de la présence." Paper presented at Journées d'études Effets de présence, effets du réel, Université du Québec à Montréal, Montreal, (6 June 2008). This text is publish, with minimal variations, in Perception et sismographie de la présence. In Le réel à l'épreuve des technologies, directed by Josette Féral, 236-259. Rennes, Presses de l'Université de Rennes, 2013a.

"The perception is a prism: Body, presence and technologies." Brazilian Journal on Presence Studies, no. 4: 2 (2014): 174-204. Disponível em www.seer.ufrgs.br/presenca (consultado em 25 de Janeiro de 2015).

- Bodysoundscape. Perception, movement and audiovisual developments in contemporary dance." In The Oxford Handbook of Music, Sound and Image in the Fine Arts, edited by Yael Kaduri. Oxford: Oxford University Press, 2016.

QUINZ, Emanuele \& MENICACCI, Armando. "Étendre la perception? Biofeedback et transferts intermodaux en danse". In Nouvelles de Danse, no. 53, Scientifiquement Danse; Quand la danse puise aux sciences et réciproquement, 76-96. Bruxelles: Contredanse, 2006.

RIEUSSET-LEMARIE, Isabelle. "À la recherche du corps perdu: au-delà des malentendus, le dialogue privilégié entre danse et arts numériques." In Bains numériques \#1: Danse et nouvelles technologies. Enghiens les Bains/2005, Biennale internationale de la scène numérique, edited by Andrea Davidson, 87-98. Madrid: Editions Centre des arts d'Enghien-les-bains, 2005.

ROLNIK, Suely. "O outro faz parte da obra ou a obra faz parte do outro?" Conference presented at the Forum F.A.Q. - Perguntas Sobre Arte, Consciência e tecnologia, SESC. /Premio Sergio Motta de Arte e tecnologia, São Paulo, Brazil, (30 de Novembro de 2006). 
"Anthropophagic subjectivity." (n.d. a). Available at http://caosmose.net/suelyrolnik/textos.htm (consultado em 22 de Maio de 2007).

"Figures nouvelles du chaos; les mutations de la subjectivité contemporaine." (n.d. b). Available at http://caosmose.net/suelyrolnik/textos.htm (consultado em 22 de May de 2007).

ROUX, Céline. Danse(s) performative(s): enjeux et développements dans le champ chorégraphique français 1993-2003. Paris: L'Harmattan, Collection Le corps en question, 2007.

SHARIR, Yacov. Beyond the Electronic Connection. The Technologically Manufactured CyberHuman and Its Physical Human Counterpart in Performance: A Theory Related to Convergence Identities. Ph.D. Thesis. Plymouth: University of Plymouth, 2012.

SHUSTERMAN, Richard. "Intellectualism and the field of aesthetics : the return of the repressed? " In Revue Internationale de Philosophie 2, no. 220, 327-342. Association Revue internationale de philosophie, 2002. Available at www.cairn.info/revue-internationale -de-philosophie-2002-2page327.htm. (consultado em 2 de Agosto de 2016).

SIMONDON, Gilbert, $([1969,1989]$ 2001). Du monde d'existence des objets techniques. Paris: Editions Aubier. Publicado originalmente em 1958.

SUQUET, Annie. "Scènes. Le corps dansant: un laboratoire de la perception." In Courtine, JeanJacques (ed.), Histoire du corps. 3. Les mutations du regard. Le XXe siècle, 407-430. Paris: Editions du Seuil, Collection Points Histoires, 2006.

VIGARELLO, Georges. "S'entraîner." In Courtine, Jean-Jacques (ed.), Histoire du corps. 3. Les mutations du regard. Le XXe siècle, 169-208. Paris: Editions du Seuil, Collection Points Histoires, 2006.

Artigo recebido em maio de 2017. Aprovado em julho de 2017. 